ISSN 2447-9071

doi https://doi.org/10.36414/rbmc.v6i16.62
Contato para correspondência: Alessandra Marques Cardoso

E-mail:

alemarquespuc@gmail.com

Conflito de interesse: Não

Financiamento: Recursos próprios

Recebido: $10 / 11 / 2020$

Aprovado: 20/11/2020

\section{Experimentação de diferentes métodos para conservação de coletâneas fúngicas}

\section{Experimentation of different methods for preserving micological collections}

\author{
Larissa de Paula Costa', Matheus Entony Bernardo Mota', Alessandra Marques \\ Cardoso $0^{1,2,3}$ \\ 'Pontifícia Universidade Católica de Goiás - PUC Goiás \\ ${ }^{2}$ Faculdade da Polícia Militar - FPM \\ ${ }^{3}$ Secretaria de Estado da Saúde de Goiás - SES-GO
}

\section{Resumo}

Amicologiaéimportante para a humanidade, proporcionando avanços científicos como a criação de antibióticos, tendo relevância em pesquisas que movimentam a medicina, indústrias farmacêuticas, agricultura e veterinária. Os fungos possuem morfologia complexa e necessitam constantemente de avaliações para conhecimento dos seus efeitos benéficos e nocivos. Assim, pesquisadores buscam métodos de conservação que mantenham a integridade morfofisiológica de culturas fúngicas. Neste contexto, nosso estudo objetivou realizar uma pesquisa qualitativa, por um período de 180 dias, avaliando três diferentes métodos de conservação de culturas fúngicas, com a finalidade de criação e manutenção de uma micoteca. Na metodologia adotada foram utilizadas quatro cepas fúngicas: Cryptococcusspp., Microsporum spp., Rhodotorula spp. eTrichophyton spp., as quaisforam conservadas pelos métodos:água destilada estéril (Método de Castellani), óleo mineral estérile repiques contínuos emÁgar Sabouraud e Mycosel. Ao término da realização dos testes, a técnica que apresentouo melhor resultado foi a conservação em água destilada estéril, apresentando como vantagens: baixo custo, facilidade de execução, acondicionamento em pequenos espaços, ausência de contaminantes e conservação satisfatória da integridade fúngica. Oestudo confirmou a eficácia do método de conservação em água destilada estéril na manutenção de coletâneas fúngicas.

Palavras-Chave: Conservação de culturas fúngicas, Micoteca, Banco de cepas fúngicas.

\begin{abstract}
A mycology holds a great importance for a humanity, providing scientific advances such as the creation of antibiotics, then focusing on researches that are a medicine, pharmaceutical, agriculture and veterinary. The fungi have a complex morphology, which constantly requires new evaluations to be fully aware of the harmful and beneficial effects that they are, so researchers are constantly seeking conservation methods that maintain their morphophysiological integrity. Our objective is to conduct a qualitative research, evaluating three different methods of preserving fungal cultures, with the purpose of creating and maintaining a mycological collection. In the methodology adopted, the fungal strains Cryptococcus spp., Microsporum spp., Rhodotorula spp. and Trichophyton spp. were used, which were conserved in different methods: sterile distilled water (Castellani method), sterile mineral oil and by repiques on Sabouraud and Mycosel Agar. At the end of the tests, the technique that presented the best result was the preservation in sterile distilled water, with advantages: Iow level, ease of execution, packing in small spaces, absence of contaminants and satisfactory preservation of fungal integrity. The study confirmed the effectiveness of the conservation method in sterile distilled water in the maintenance of fungal collections.
\end{abstract}

Keywords: Conservation of fungal cultures, Mycological collections, Fungal strain's bank. 


\section{Introdução}

Os fungos são seres vivos heterotróficos, eucarióticos, unicelulares como as leveduras, ou multinucleados, como os fungos filamentosos. Possuem estruturas macroscópicas (cogumelos) ou microscópicas (leveduras e bolores), sendo capazes de crescer em qualquer meio que possua nutrientes, temperatura e umidade adequados ${ }^{1}$.

O Reino Fungi vem sendo alvo de pesquisas ao longo dos anos, principalmente em busca de mais conhecimento sobre os efeitos nocivos e benéficos que ele apresenta. Dentre esses estudos, obteve-se a grande contribuição para o tratamento de enfermidades bacterianas, sendo utilizados seus substratos para a produção de antibióticos. Por isso, métodos eficientes de conservação de culturas fúngicas são tão importantes ${ }^{2,3}$.

A micologia é o ramo da ciência com grande importância no reino animal e vegetal, movimentando a medicina, indústrias farmacêuticas, agricultura e veterinária. Os fungos despertam interesse científico devido tanto às suas características benéficas (são utilizado na produção de alimentos e medicamentos) quanto maléficas (causam doenças em humanos, animais e vegetais) ${ }^{4}$.

Dentre os métodos de conservação fúngica destaca-se a técnica proposta por Castellani em 1939, a qual tem por objetivo conservar culturas fúngicas em água destilada à temperatura ambiente, acondicionando-as em pequenos frascos de vidro âmbar. A literatura afirma tratar-se de uma técnica de fácil reprodução, baixo custo e bastante vantajosa por apresentar pequena influência de microrganismos contaminantes e por requerer pequeno espaço físico para conservação de inúmeras variedades fúngicas ${ }^{5-10}$.

A técnica de conservação em óleo mineral estéril baseia-se no princípio de limitar a quantidade de oxigênio disponível sobre uma cultura fúngica, obtendo uma redução no seu metabolismo, alcançado a estabilidade entre crescimento e morte fúngica. Desse modo, diminui-se a desidratação do meio de cultura, e consequentemente, aumenta-se a longevidade das cepas, mantendo-as viáveis entre dois e três anos ${ }^{11}$.

$\mathrm{O}$ repique contínuo, considerada uma técnica bastante utilizada, baseia-se na transferência de fragmentos de culturas fúngicas para um meio de cultura virgem, em períodos determinados. Embora o repique contínuo consuma tempo e apresente vulnerabilidade à microrganismos contaminantes, é uma opção para pequenas coleções de culturas que são constantemente utilizadas em curtos períodos de tempo, como aqueles inferiores a um ano'.

A conservação de culturas fúngicas em laboratórios possibilita descobertas e/ou aprofundamento de conhecimento sobre micoses e/ou medicamentos que podem ser produzi- dos por esses microrganismos ${ }^{12,13}$. Ressaltamos que um dos empecilhos no estudo dos agentes fúngicos são os repiques contínuos e as contaminações por bactérias e fungos anemófilos, os quais podem ocasionar perda de cepas, desperdício de insumos e gastos desnecessários ${ }^{14-17}$.

Nesse contexto, nosso estudo objetivou realizar uma pesquisa qualitativa, avaliando três diferentes métodos de conservação de culturas fúngicas, com a finalidade de criação e manutenção de uma micoteca, contribuindo com informações sobre a manutenção de culturas fúngicas para diversas finalidades, dentre elas ensino e pesquisa.

\section{Métodos}

\section{Preparo das coletâneas fúngicas}

Para a avaliação de três diferentes métodos de conservação fúngica foram utilizadas duas leveduras (Rhodotorula spp. e Cryptococcus spp.) e dois fungos filamentosos (Microsporum canis e Trichophyton spp.) oriundos da Micoteca da Seção de Microbiologia do Laboratório Clínico da PUC Goiás (LAC/ PUC Goiás). Esses microrganismos foram semeados em Ágar Sabouraud e incubados por 15 dias à temperatura ambiente, para posteriormente serem submetidos aos experimentos de conservação fúngica, os quais foram realizados durante um período de 180 dias, entre outubro de 2016 e abril de 2017.

\section{Conservação em água destilada estéril}

Adotando-se o método de Castellani6 com algumas modificações, foram autoclavados $200 \mathrm{~mL}$ de água destilada, e subsequentemente, foram transferidos $1 \mathrm{~mL}$ para cada um dos 20 criotubos estéreis, os quais foram acondicionados em caixas de policarbonato, sendo cinco criotubos para cada cepa, que foram divididas em cinco grupos de acordo com o período de leitura do experimento $(60,90,120,150$ e 180 dias). Foram transferidos, para cada criotubo com $200 \mathrm{~mL}$ de água destilada esterilizada, 0,5 por $0,5 \mathrm{~mm}^{2}$ de culturas fúngicas previamente cultivadas em Ágar Sabouraud. Após, avaliou-se a viabilidade fúngica por meio de repiques em tubos com Ágar Sabouraud após 60, 90, 120, 150 e 180 dias de armazenamento à temperatura ambiente, para cada uma das quatro cepas testadas, individualmente $\mathrm{e}^{6,17-19}$.

\section{Conservação em óleo mineral estéril}

Para a avaliação do método do óleo mineral estéril, testouse a conservação de culturas fúngicas em tubo após um período de 180 dias de armazenamento. Óleo mineral autoclavado foi vertido pela parede dos tubos $(20 \times 150 \mathrm{~mm})$ até alcançar o ápice do Ágar Sabouraud das culturas das quatro 
cepas fúngicas em estudo, no $15^{\circ}$ dia de crescimento. Os experimentos foram armazenados à temperatura ambiente por 180 dias, e observados semanalmente quanto aos aspectos macroscópicos das culturas. Após o período descrito, avaliouse a viabilidade fúngica por meio de repiques em tubos com Ágar Sabouraud ${ }^{20-22}$.

\section{Conservação a partir de repiques contínuos em Ágar Sabouraud e Ágar Mycosel}

Inicialmente foram realizados repiques mensais. Após 60 dias, os repiques foram realizados quinzenalmente $(75,90,105$, 120, 135, 150, 165 e 180 dias), sendo utilizado Ágar Sabouraud para leveduras e Ágar Mycosel para fungos filamentosos, transferindo-se fragmentos de colônias para um meio de cultura virgem, em tubos de ensaio, possibilitando a avaliação do crescimento fúngico sob temperatura ambiente ${ }^{23}$.

\section{Resultados}

Os resultados dos experimentos realizados nesse estudo evidenciaram que a técnica que apresentou o melhor resultado foi a conservação em água destilada estéril, apresentando como vantagens: baixo custo, facilidade de execução, acondicionamento em pequenos espaços, ausência de contaminantes e conservação satisfatória da integridade fúngica. Os resultados obtidos encontram-se apresentados detalhadamente nas Tabelas 1, 2 e 3.

Tabela 1. Resultados obtidos com a conservação de quatro cepas fúngicas em água destilada estéril, nos períodos de 60, $90,120,150$ e 180 dias.

\begin{tabular}{llllll}
\hline Espécies & \multicolumn{5}{c}{ Dias } \\
\hline Cryptococcus spp. & $\mathbf{6 0}$ & $\mathbf{9 0}$ & $\mathbf{1 2 0}$ & $\mathbf{1 5 0}$ & $\mathbf{1 8 0}$ \\
Microsporum canis & $\mathrm{CP}$ & $\mathrm{CP}$ & $\mathrm{CP}$ & $\mathrm{CP}$ & $\mathrm{CP}$ \\
Rhodotorula spp. & $\mathrm{CP}$ & $\mathrm{CP}$ & $\mathrm{CP}$ & $\mathrm{CP}$ & $\mathrm{CP}$ \\
Trichophyton spp. & $\mathrm{CP}$ & $\mathrm{CP}$ & $\mathrm{CP}$ & $\mathrm{CP}$ & $\mathrm{CP}$ \\
\hline
\end{tabular}

Legenda: $\mathrm{CP}=$ crescimento fúngico positivo, com ausência de microrganismos contaminantes.
Tabela 2. Resultados obtidos com a conservação de quatro cepas fúngicas em óleo mineral estéril, no período de 180 dias.

\begin{tabular}{lc}
\hline Espécies & Dias \\
\hline Cryptococcus spp. & $\mathbf{1 8 0}$ \\
Microsporum canis & $\mathrm{CP}$ \\
Rhodotorula spp. & $\mathrm{CN}$ \\
Trichophyton spp. & $\mathrm{CN}$ \\
\hline
\end{tabular}

Legenda: $\mathrm{CP}=$ crescimento fúngico positivo, com ausência de microrganismos contaminantes; $\mathrm{CN}=$ ausência de crescimento fúngico.

Tabela 3. Resultados obtidos com a conservação de quatro cepas fúngicas por repique contínuo, nos períodos de 30,60, $75,90,105,120,135,150,165$ e 180 dias.

\begin{tabular}{lcccccccccc}
\hline Espécies & $\mathbf{3 0}$ & $\mathbf{6 0}$ & $\mathbf{7 5}$ & $\mathbf{9 0}$ & $\mathbf{1 0 5}$ & $\mathbf{1 2 0}$ & $\mathbf{1 3 5}$ & $\mathbf{1 5 0}$ & $\mathbf{1 6 5}$ & $\mathbf{1 8 0}$ \\
\hline $\begin{array}{l}\text { Cryptococ- } \\
\text { cus spp. }\end{array}$ & $\mathrm{CP}$ & $\mathrm{CP}$ & $\mathrm{CP}$ & $\mathrm{CP}$ & $\mathrm{CP}$ & $\mathrm{CP}$ & $\mathrm{CP}$ & $\mathrm{CP}$ & $\mathrm{CP}$ \\
$\begin{array}{l}\text { Microspo- } \\
\text { rum canis }\end{array}$ & $\mathrm{CP}$ & $\mathrm{CP}$ & $\mathrm{CP}$ & $\mathrm{CP}$ & $\mathrm{CP}$ & $\mathrm{CP}$ & $\mathrm{CP}$ & $\mathrm{CP}$ & $\mathrm{CP}$ & $\mathrm{CP}$ \\
$\begin{array}{l}\text { Rhodoto- } \\
\text { rula spp. }\end{array}$ & $\mathrm{CP}$ & $\mathrm{CP}$ & $\mathrm{CP}$ & $\mathrm{CP}$ & $\mathrm{CP}$ & $\mathrm{CP}$ & $\mathrm{CP}$ & $\mathrm{CP}$ & $\mathrm{CP}$ \\
$\begin{array}{l}\text { Tricho- } \\
\text { phyton } \\
\text { spp. }\end{array}$ & $\mathrm{CP}$ & $\mathrm{CP}$ & $\mathrm{CP}$ & $\mathrm{CP}$ & $\mathrm{CP}$ & $\mathrm{CP}$ & $\mathrm{CP}$ & $\mathrm{CP}$ & $\mathrm{CP}$ & $\mathrm{CP}$ \\
\hline
\end{tabular}

Legenda: $\mathrm{CP}=$ crescimento fúngico positivo, com ausência de de microrganismos contaminantes; $\mathrm{CP}^{*}=$ crescimento fúngico positivo, com presença de contaminantes do gênero Aspergillus spp.

\section{Discussão}

Os resultados apresentados neste estudo mostraram-se satisfatórios, sobretudo o método de conservação em água destilada estéril, conforme vem sendo observado ao longo dos anos, de acordo com Castellani6 e Jones e colaboradores12, revelando-se uma técnica ainda utilizada atualmente, segundo Guimarães ${ }^{17}$.

Desse modo, constatamos com os experimentos realizados os seguintes benefícios na utilização do método de conservação em água destilada estéril: possibilidade de armazenamento em pequeno espaço físico à temperatura ambiente, baixo custo do material utilizado, facilidade na execução da técnica, e conservação da integridade macroscópica e microscópica 
fúngica, com ausência do aparecimento de microrganismos contaminantes.

Quanto ao experimento utilizando óleo mineral estéril, após o período de 180 dias observamos êxito na conservação de apenas uma das quatro cepas fúngicas avaliadas. Ou seja, a viabilidade macroscópica e microscópica após repique em Ágar Sabouraud foi obtida apenas para a levedura Cryptococcus spp. Em relação às outras espécies avaliadas (Microsporum canis, Rhodotorula spp., Trichophyton spp.) foi observada ausência de crescimento, e durante o período de armazenamento dos experimentos, observamos redução do volume do óleo mineral nos tubos e consumo do ágar, características outrora não observadas na cultura de Cryptococcus spp.

Durante a realização dos experimentos com o óleo mineral estéril, foram evidenciadas mudanças no aspecto macroscópico da cepa de Rhodotorula spp. As colônias tipicamente pigmentadas com a coloração alaranjada/salmão e aspecto rugoso24, apresentaram-se após 20 dias da adição do óleo mineral estéril, coloração creme e aspecto liso, conforme ilustrado na Figura 1.

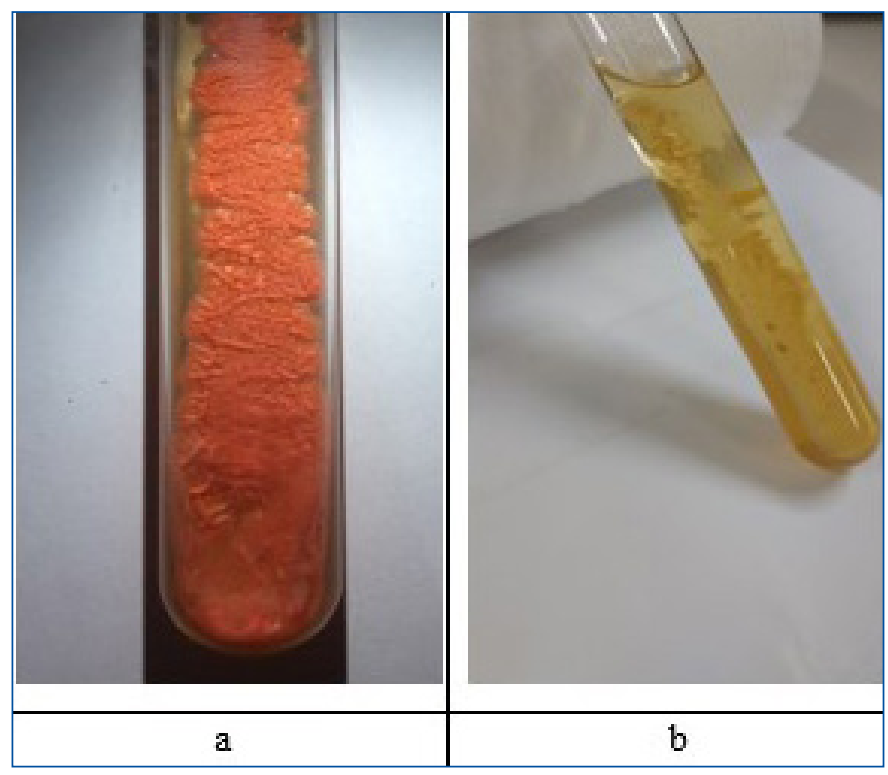

Figura 1. Aspecto macroscópico da cepa de Rhodotorula spp. antes (a) e 20 dias após (b) a adição do óleo mineral estéril.

Sobre os repiques contínuos, ficou evidente que após períodos prolongados ( 30 e 60 dias), as culturas das leveduras em Ágar Sabouraud tornaram-se propensas a contaminação por Aspergillus spp. Com a mudança da realização dos repiques de mensal para quinzenalmente, foi possível evitar o crescimento de microrganismos contaminantes. Devido à utilização do Ágar Sabouraud acrescido de cloranfenicol e cicloheximida (Ágar Mycosel) nas culturas dos fungos filamentosos, não foi observada presença de contaminantes durante os experimentos 25 .

A técnica de repiques contínuos revelou-se satisfatória, porém laboriosa e mais vulnerável à interferência de microrganismos contaminantes. Além de, em comparação às demais técnicas avaliadas, necessitar de maior espaço físico para armazenamento e ser mais onerosa, requerendo maior quantidade de meio de cultura para sua realização.

\section{Conclusão}

Concluímos que, dentre os métodos avaliados, a técnica que apresentou o melhor resultado foi a conservação em água destilada estéril, apresentando as vantagens, como baixo custo, facilidade de execução, possibilidade de acondicionamento em pequenos espaços físicos, ausência de interferência de microrganismos contaminantes e conservação satisfatória da integridade das culturas fúngicas.

\section{Referências}

1. Cavalcanti SDB. Aplicação de metodologias de preservação e caracterização de fungos na coleção de culturas do Instituto de Medicina Tropical de São Paulo. Dissertação (Mestrado) - Programa de Dermatologia, Faculdade de Medicina de São Paulo. São Paulo. 2010;74p.

2. Cavalcanti SDB. Aplicação de metodologias de preservação e caracterização de fungos na coleção de culturas do Instituto de Medicina Tropical de São Paulo. Dissertação (Mestrado) - Programa de Dermatologia, Faculdade de Medicina de São Paulo. São Paulo. 2010;74p.

3. Lackner $\mathrm{G}$, Hertweck C. Endofungal bacteria as producers of mycotoxins. Cell Picture Show. 2009;17(12):570-6.

4. Medeiros FHV, Martins SJ, Zucchi TD, Melo IS, Batista LR, Machado JDC. Controle biologico de fungos de armazenamento produtores de micotoxinas. Ciênc. agrotec. 2012;36(5):483-97.

5. Oliveira JC. Tópicos em Micologia Médica. 4. ed. Rio de Janeiro: [s.n.].

6. Aparecido CC, Egydio APM, Figueiredo MB. Avaliação de três diferentes métodos utilizados na Micoteca do Instituto Biológico de São Paulo para preservação de fungos fitopatogênicos. Summa Phytopathol. 2001;27:421-4.

7. Castellani A. Viability of some pathogenic fungi in distilled water. J. trop. Med. Hyg. 1939;42:225-6. 
8. Castellani A. A brief note on the viability of some pathogenic fungi in sterile distilled water and a simple method to maintain fungal strains in mycological collections, preventing pleomorphism. Impr. Med. 1960a;24:270-2.

9. Castellani A. Persistency and variations in the cultural an biochemical characters of certain fungi of human origin isolated two, theree, four and five decades ago. Impr. med. 1960b;24:392-6.

10. Castellani A. The water cultivation of pathogenic fungi. Ann. Soc. Belge Med. Trop. 1964;44(2):217-220.

11. Castellani A. Maintenance and cultivation of the common pathogenic fungi of man in sterile distilled water. J. Trop. Med. Hyg. 1967;70:181-4.

12. Sola MC, Oliveira AP, Feistel JC, Rezende CSM. Manutenção de microrganismos: conservação e viabilidade. enciclopedia biosfera: centro científico conhecer. 2012;8(14):1398-418.

13. Jones RJ, Sizmur KJ, Wildman HG. A miniaturised system for storage of fungal cultures in water. Mycologist. 1991;5(4):184-6.

14. Ruiz LS, Pereira VBR. Importância dos fungos no ambiente hospitalar. Bol Inst Adolfo Lutz. 2016;26(2):2-4.

15. Backes LTH, Naumann VLD, Calil LN. Isolamento de fungos anemófilos em biblioteca e prevalência de alergias respiratórias. Rev. Panam. Infectol. 2011;13(3):19-25.

16. Mezzari A, Perin C, Junior SAS, Bernd LAG, Di Gesu G. Os fungos anemófilos e sensibilização em indivíduos atópicos em Porto Alegre, RS. Revista da Associação Médica Brasileira. 2003;49(3):270-3.

17. Rêgo CM, Santos FS. Ocorrência de fungos anemófilos e sua relação com fatores abióticos em Barreiras, Bahia. Revista Brasileira de Biociências. 2015;13(4):265-71.

18. Guimarães LC. Métodos de preservação de fungos potencialmente toxigênicos, Dissertação (Mestrado) - Programa de Pós-Graduação em Ciência dos Alimentos, Universidade Federal de Lavras. Minas Gerais. 2011;55p.

19. Diogo HC, Sarpieri A, Pires MC. Preservação de fungos em água destilada. Anais Brasileiros de Dermatologia. 2005;80(6):591-4.

20. Rodrigues EG, Lírio VS, Lacaz CDS. Preservação de fungos de interesse médico em água destilada. Revista Inst. Med. Tropical. 1992;34(2):159-65.

21. Minami PS. Micologia: métodos laboratoriais de diagnóstico das micoses. São Paulo: [s.n.].

22. Nakasone KK, Peterson SW, Jong SC. Preservation and Distribution of Fungal Cultures. San Diego, California
- USA: [s.n.].

23. Panizo MM, Reviakina V, Montes W, Gonzales G. Mantenimiento y Preservacion de hongos en agua destilada y aceite mineral. Revista de la Sociedad Venezolana de Microbiologia. 2005;25(1):35-40.

24. Passador MM, Pires GCC, Finatti D, Aparecido CC, Figueiredo MB. Manutenção da viabilidade e patogenicidade de culturas mantidas na micoteca "Mário Barreto Figueiredo". Biológico. 2010;72(1):51-5.

25. Sicilia MJL, Cuesta FS. Identificacion de Leveduras. Rev Iberoam Micol. 2007;3:1-20.

26. Agência Nacional de Vigilância Sanitária - ANVISA. Descrição dos Meios de Cultura Empregados nos Exames Microbiológicos Módulo IV, 2004. Disponível em: <http://www.anvisa.gov.br/servicosaude/microbiologia/mod_4_2004.pdf> 